\title{
KARAKTERISASI MIKROPLASTIK DARI SEDIMEN PADANG LAMUN, PULAU PANJANG, JEPARA, DENGAN FT-IR INFRA RED
}

\author{
Kamelia Lestari ${ }^{1)}$, Haeruddin ${ }^{2)}$, Oktavianto Eko Jati ${ }^{1)}$ \\ 1) Program Studi Manajemen Sumberdaya Peraira, Universitas Diponegoro, Semarang, \\ 2) Departemen Sumberdaya Akuatik, Universitas Diponegoro, Semarang \\ Email: kamelia732@gmail.com
}

\begin{abstract}
Abstrak
Ekosistem lamun Pulau Panjang memiliki fungsi ekologis bagi biota sekitarnya. Mikroplastik dapat tersimpan di sedimen untuk jangka waktu yang lama karena sifatnya yang sulit terurai. Penelitian ini bertujuan untuk mengetahui keberadaan mikroplastik pada sedimen lamun di Pulau Panjang. Penelitian ini dilaksanakan pada bulan Mei 2019 di Pulau Panjang, Jepara. Metode yang digunakan dalam penelitian ini adalah metode survei. Teknik pengambilan sampel menggunakan metode random sampling, dibagi menjadi 2 jenis sampel yaitu 7 sampel inti dan 3 sampel tambahan (untuk uji FT-IR). Analisis dilakukan untuk mengetahui keterkaitan antara jumlah mikroplastik yang didapatkan dengan kerapatan lamun. Berdasarkan hasil penelitian, dapat disimpulkan bahwa jumlah total mikroplastik yang didapatkan sebanyak 93 partikel dengan bentuk fragmen, film, fiber, dan pelet. Jumlah tertinggi terdapat pada titik 7 dengan jumlah 19 partikel. Bentuk mikroplastik dominan yang ditemukan yaitu fragmen sebanyak 51 partikel (54,83\%), kemudian bentuk lain seperti fiber 34 partikel (36,56\%) dan film sebanyak 8 partikel (8,6\%). Jenis lamun yang ditemukan yaitu Cymodocea rotundata, Cymodocea serrulata, dan Enhalus acoroides. Kerapatan lamun di Pulau Panjang titik 1-7 tergolong tinggi, kecuali pada titik 5 yang memiliki kerapatan lamun sedang. Analisa statistika yang dilakukan yaitu uji One Way ANOVA dengan nilai signifikansi 0,008 $(<0,05)$ yang menunjukkan bahwa rata-rata bentuk mikroplastik yang ditemukan setiap titik berbeda secara signifikan. Berdasarkan uji FT-IR yang telah dilakukan terhadap sampel A, sampel B dan sampel C didapatkan puncak bilangan gelombang khas berkisar $1466-3700 \mathrm{~cm}-1$ dengan gugus fungsi berupa ikatan $\mathrm{C}, \mathrm{C}=\mathrm{C}, \mathrm{C}=\mathrm{O}, \mathrm{N}-\mathrm{H}, \mathrm{OH}$ dan $\mathrm{C}-\mathrm{H}$ yang menggambarkan ikatan plastik jenis $P P$.
\end{abstract}

Kata Kunci: Fiber, Film, Fragmen, Mikroplastik, Lamun Pulau Panjang, Pelet

\begin{abstract}
Panjang Island seagrass ecosystem has an ecological function for the surrounding biota. Microplastics can be stored in sediments for a long time because of their difficult to decompose. This study aims to determine the presence of microplastics in seagrass sediments on Panjang Island. This research was conducted in May 2019 on Pulau Panjang, Jepara. The method used in this research is a survey method. The sampling technique used the random sampling method, divided into 2 types of samples, namely 7 core samples and 3 additional samples (for the FT-IR test). The analysis was conducted to determine the relationship between the amount of microplastic obtained and the density of the seagrass. Based on the research results, it can be concluded that the total number of microplastics obtained was 93 particles in the form of fragments, films, fibers, and pellets. The highest number is at point 7 with 19 particles. The dominant microplastic forms found were fragments of 51 particles (54.83\%), then other forms such as fiber 34 particles (36.56\%) and film as many as 8 particles (8.6\%). The types of seagrass found were Cymodocea rotundata, Cymodocea serrulata, and Enhalus acoroides. The seagrass density in Panjang Island from points 1-7 is high, except at point 5 which has medium seagrass density. The statistical analysis carried out was the One Way ANOVA test with a significance value of $0.008(<0.05)$ which indicated that the average shape of the microplastics found in each point was significantly different. Based on the FT-IR test that has been carried out on sample A, sample B and sample $C$, the typical peak wave number ranges from $1466-3700 \mathrm{~cm}-1$ with functional groups in the form of bonds $C, C=C, C=O, N H, O H$ and $\mathrm{CH}$ which describes the PP type plastic bond.
\end{abstract}

Keywords: Fiber, Film, Fragments, Microplastics, Pulau Panjang Seagrass, Pellets 


\section{PENDAHULUAN}

Keberlanjutan kualitas perairan dan laut sebagai pemberi kehidupan bagi ekosistem, ekonomi, serta masyarakat luas, rentan oleh ancaman pencemaran plastik (Puteri et al. 2018). Di laut terdapat berbagai ekosistem diantaranya lamun, karang, mangrove hingga ekosistem laut dalam. Isu pencemaran plastik di lingkungan perairan telah menjadi perhatian global saat ini karena dampaknya yang merugikan ekosistem perairan laut dan pantai. Terlebih lagi dengan terurainya sampah plastik menjadi partikel plastik lebih kecil yang berukuran mikrometer (mikroplastik) dan nanometer (nanoplastik), memungkinkan partikel halus dapat masuk ke rantai makanan dan berujung pada manusia sebagai predator paling atas dalam rantai makanan (Widianarko dan Hantoro, 2018).

Sifat plastik yang lama untuk terurai membuat jumlah plastik di perairan menumpuk seiring berjalannya waktu dan dapat berakibat lingkungan menjadi terganggu serta membahayakan biota bahkan manusia. Mikroplastik dapat masuk ke jaringan tubuh salah satunya melalui getah bening yang kemudian masuk ke peredaran darah dan partikel berukuran $>1,5 \mu \mathrm{m}$ akan menyumbat pembuluh kapiler terkecil yang hanya berdiameter beberapa $\mu \mathrm{m}$ (Yoo et al., 2011; Hollman et al., 2013).

Plastik yang dasarnya tidak dapat dicerna, hanya akan terakumulasi di tubuh biota. Meskipun berukuran kecil, namun konsumsi mikroplastik dapat mentransfer pencemar ke jaringan tubuh biota yang berakibat terganggunya fungsi ekofisiologis terkait dengan kesehatan dan keanekaragaman hayati (Ruiz et al., 2016). Jumlah sampah yang melimpah di perairan diakibatkan oleh beberapa hal diantaranya limbah domestik, industri serta adanya aktivitas manusia di perairan, seperti menangkap ikan menggunakan jala yang terbuat dari serat plastik.

Pulau Panjang adalah salah satu pulau yang terletak di Kabupaten Jepara, Jawa Tengah. Pulau Panjang memiliki karakteristik yaitu pasir pantainya yang berwarna putih dan terdapat hutan tropis di tengah pulau. Menurut Dinas Pariwisata dan Kebudayaan Kabupaten Jepara, Pulau Panjang dikontrakkan kepada pihak asing selama lebih dari 30 tahun dimulai pada tahun 1987 (PPK-KP3K), hal ini berdampak Pulau Panjang menjadi kurang terawat dan pengembangan pulau menjadi terhambat. Pulau Panjang adalah salah satu wisata bahari yang didalamnya terdapat ekosistem penting seperti karang dan lamun, sehingga kelestariannya perlu dijaga. Adanya kegiatan pariwisata ini dapat menghasilkan sampah plastik yang 
mengganggu lingkungan. Plastik yang dijumpai di Pulau Panjang berupa bungkus makanan, minuman, botol, sedotan dan lainnya. Banyaknya wisatawan dapat membuat produksi sampah menjadi lebih banyak. Menurut Miswanto dan Safaat (2018), dijelaskan bahwa banyaknya jumlah wisatawan berbanding lurus dengan jumlah sampah yang dihasilkan. Sampah berukuran besar yang berserakan, terkena limpasan air, terpecah menjadi mikroplastik yang selanjutnya menyebar ke permukaan laut, di kolom air dan di sedimen, bahkan di laut dalam (Woodall et al., 2014). Mikroplastik dapat tersimpan di sedimen untuk waktu yang lama, dan dikhawatirkan mikroplastik tersebut dapat mengancam biota, terutama biota asosiasi lamun yang hidupnya di dasar perairan (benthos). Tujuan dilakukannya penelitian ini adalah untuk mengetahui karakteristik mikroplastik pada sedimen lamun Pulau Panjang, Jepara.

\section{METODE PENELITIAN}

\subsection{Alat dan Bahan}

Alat yang digunakan pada penelitian ini adalah:

- $\quad$ Global Position System (GPS) untuk menentukan titik koordinat sampling

- $\quad$ Float tracking untuk mengukur kecepatan arus,

- $\quad$ Secchi disk untuk mengukur kedalaman dan salinorefraktometer untuk mengukur salinitas

- $\quad$ Corer (pipa plastik PVC dengan bentuk tabung silinder berukuran 40 - $50 \mathrm{~cm}$ dengan diameter 3 inch) dan cetok untuk mengambil sampel sedimen

- $\quad$ Kuadran 1 x 1 m untuk mengukur kerapatan lamun

- Wadah stainless steel untuk sampel sedimen

- $\quad$ Erlenmeyer $500 \mathrm{ml}$ untuk tempat supernatan yang sudah tersaring,

- Kertas saring Whatman nomor 42 dengan ukuran pori 2,5 $\mu \mathrm{m}$ untuk menyaring mikroplastik,

- Cawan petri sebagai tempat peletakan kertas saring Whatman,

- Hot plate magnetic stirrer merk CIMAREC SP-131320-33Q untuk memanaskan sampel,

- $\quad$ Oven untuk mengeringkan sampel,

- $\quad$ Alumunium foil sebagai alas sedimen saat dioven

- Gelas ukur untuk mengukur aquades, $\mathrm{NaCl}$ dan $\mathrm{H}_{2} \mathrm{O}_{2}$

- $\quad$ Beaker glass sebagai wadah pembuatan $\mathrm{NaCl}$ jenuh 
- $\quad$ Timbangan digital untuk menimbang sampel,

- $\quad$ Corong kaca untuk membantu penyaringan partikel mikroplastik

- $\quad$ Pinset untuk memindahkan kertas saring ke cawan petri,

- Mikroskop stereo Olympus SZ61 yang dilengkapi kamera untuk mengamati mikroplastik,

- $\quad$ Laptop

- $\quad$ FT-IR (Fourier Transform Infra Red) Perkin Elmer Frontier S/N: 96772 untuk mengidentifikasi gugus fungsi.

Bahan yang digunakan dalam penelitian ini adalah:

- Sampel sedimen (7 sampel inti dan 3 sampel tambahan) yang diperoleh dari hasil sampling di wilayah ekosistem lamun di Pulau Panjang,

- $\quad \mathrm{NaCl}$ jenuh untuk memisahkan mikroplastik dengan material lainnya yang terdapat di sampel sedimen,

- $\mathrm{H}_{2} \mathrm{O}_{2} 30 \%$ untuk menghilangkan bahan organik dalam sedimen dan aquades sebagai pengencer dan pelarut.

\subsection{Prosedur Penelitian}

Lokasi Penelitian dapat dilihat pada Gambar 1 dan pengambilan sampel sedimen dilakukan pada tanggal 4 Mei 2019. Penentuan lokasi pengambilan sampel (Gambar 2) menggunakan metode random sampling yaitu pengambilan data secara acak tanpa adanya pertimbangan tertentu, hanya saja sampel sedimen harus diambil di sekitar ekosistem lamun. Pengambilan sampel sedimen dilakukan sebanyak satu kali tanpa ada ulangan dan dilakukan pada pukul 09.00 WIB untuk mengantisipasi air pasang saat pengambilan sampel. Sampel dibagi menjadi 2 yaitu 7 sampel inti (Titik 1-7) dan 3 sampel tambahan (Sampel A, B, C). Sampel-sampel tersebut diperlakukan sama, yang membedakan hanya sampai uji FT-IR dimana sampel yang digunakan untuk uji FT-IR hanya sampel A, B dan C saja, sedangkan 7 sampel inti tidak diujikan FT-IR.

Pengambilan sedimen menggunakan pipa corer yang memiliki diameter 3 inch dengan kedalaman 15 - $20 \mathrm{~cm}$ dari permukaan substrat tergantung pada kedalaman substrat masingmasing titik. Sampel sedimen kemudian dimasukkan ke wadah stainless steel. Selain itu diukur pula beberapa parameter pendukung diantaranya kecepatan arus, kedalaman dan kerapatan lamun. Setelah sampel diperoleh, sampel sedimen selanjutnya akan di preparasi dan di ekstraksi di Laboratorium Pengelolaan Sumberdaya Ikan dan Lingkungan Universitas 
Diponegoro, untuk mengamati mikroplastik yang diperoleh akan dilakukan di Laboratorium Biologi Jurusan Ilmu Kelautan Fakultas Perikanan dan Ilmu Kelautan Universitas Diponegoro dan untuk pengujian FT-IR dilakukan di Laboratorium Fisika Universitas Negeri Semarang.

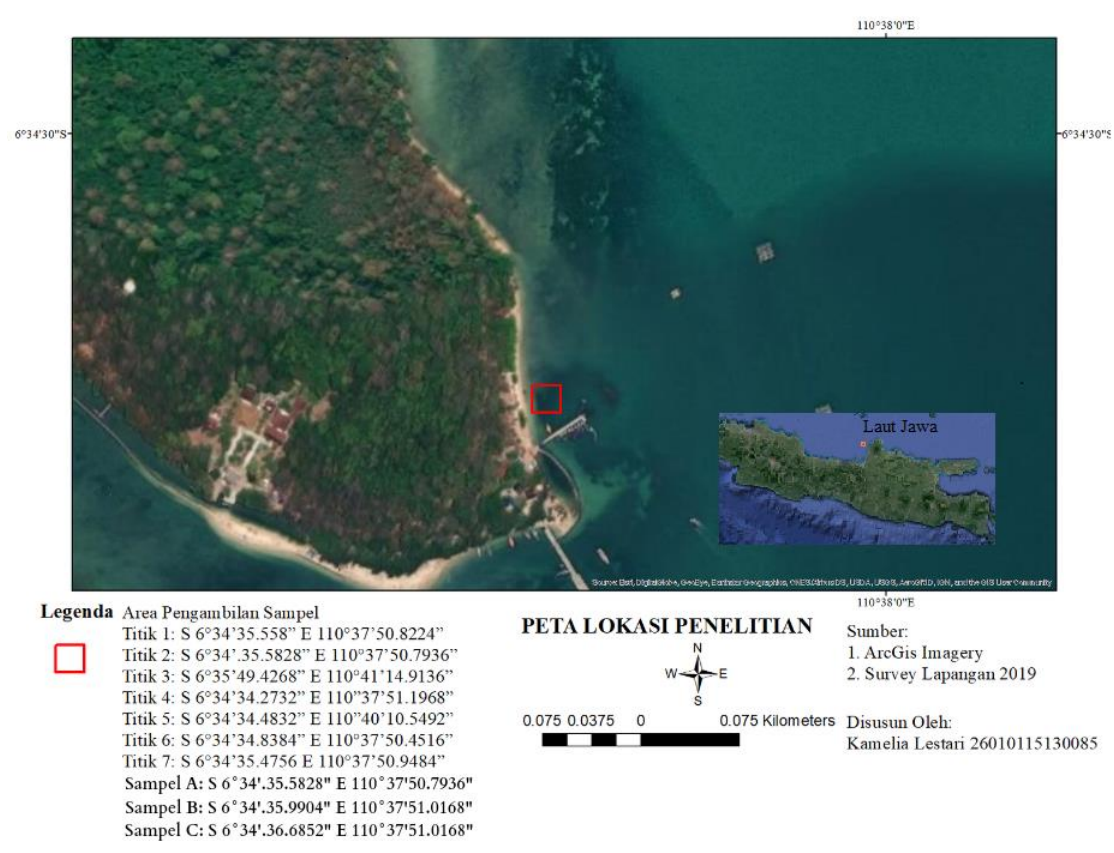

Gambar 1. Lokasi Penelitian

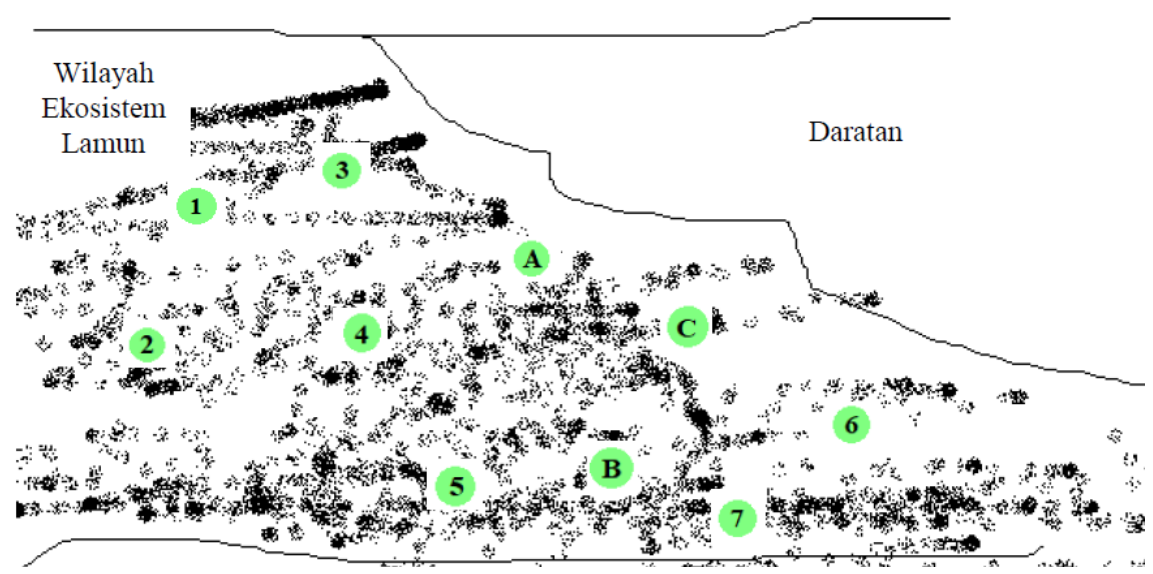

Gambar 2. Titik Pengambilan Sampel Secara Acak

\subsection{Preparasi dan Ekstraksi Sampel}

Diagram alir preparasi sampel dapat dilihat pada Gambar 3. Sampel sedimen di preparasi kemudian di ekstraksi agar mendapatkan mikroplastiknya. Sedimen yang telah diperoleh kemudian dikeringkan untuk menghilangkan kandungan air, bisa dilakukan menggunakan oven dengan suhu $75^{\circ} \mathrm{C}$ (dengan tujuan agar mikroplastik tidak meleleh atau merubah 
struktur mikroplastik) hingga antar butir sedimennya tidak saling menempel (Septian et al. 2018). Kemudian masing-masing bagian sedimen 500 gram dihilangkan bahan organiknya menggunakan $\mathrm{H}_{2} \mathrm{O}_{2} 30 \% . \mathrm{H}_{2} \mathrm{O}_{2}$ yang berkadar $50 \%$ harus diencerkan terlebih dahulu agar mendapat kadar $30 \%$ seperti yang diperlukan. Pengenceran $\mathrm{H}_{2} \mathrm{O}_{2}$ menggunakan aquades dengan volume tertentu menggunakan persamaan 1 .

$$
\mathrm{V} 1 \times \mathrm{M} 1=\mathrm{V} 2 \times \mathrm{M} 2
$$

Dimana:V1= Volume awal

$$
\begin{aligned}
& \text { M1 = Kadar/persentase awal } \\
& \text { V2= Volume yang diinginkan } \\
& \text { M2 = Kadar/Persentase yang diinginkan }
\end{aligned}
$$

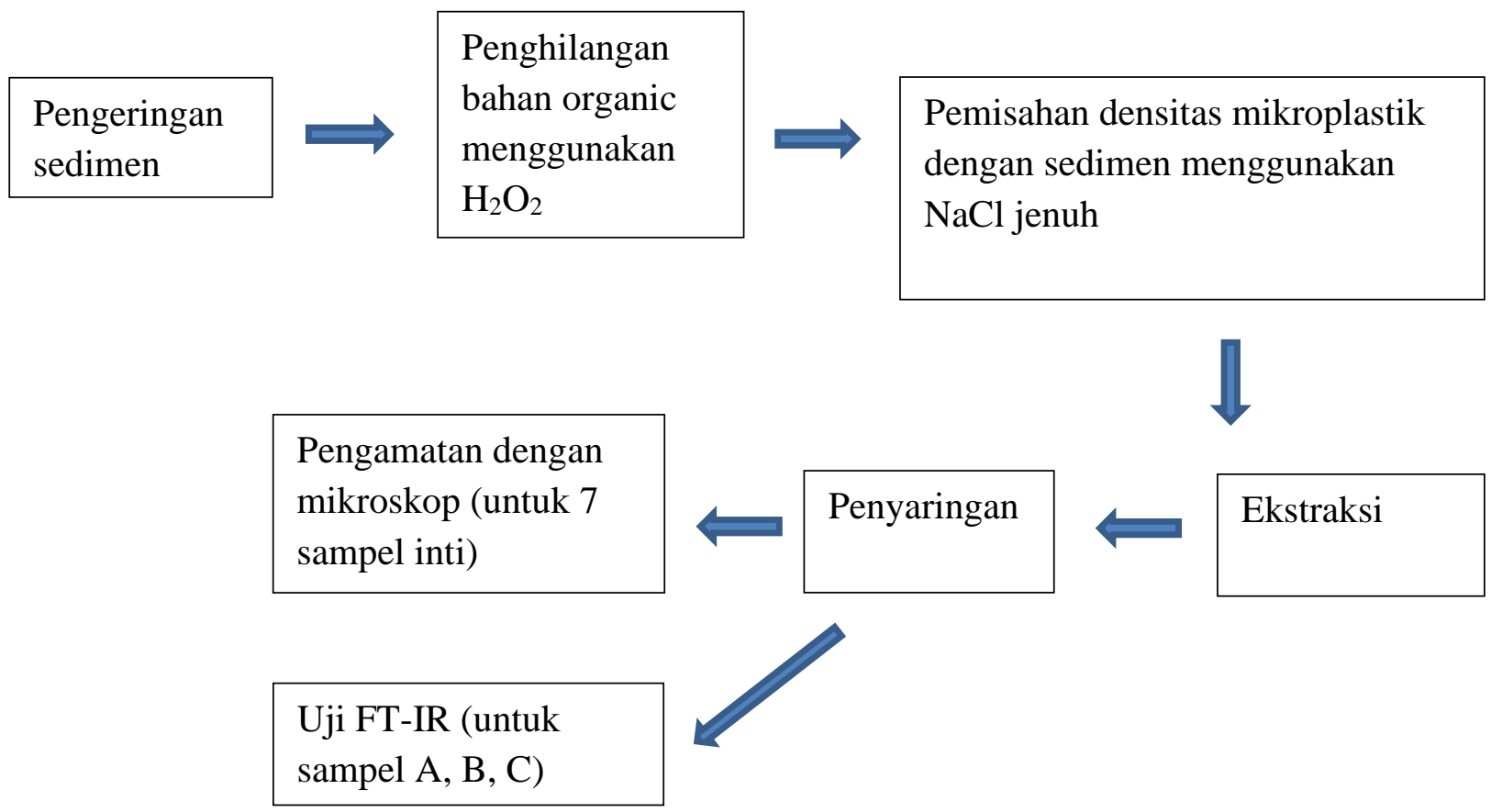

Gambar 3. Diagram Alir Preparasi Sampel

Kemudian menambahkan $\mathrm{H}_{2} \mathrm{O}_{2} 30 \%$ ke sedimen hingga terendam. Selanjutnya dipanaskan di hot plate dengan suhu $55-65^{\circ} \mathrm{C}$ untuk mempercepat proses evaporasi dari $\mathrm{H}_{2} \mathrm{O}_{2}$ (Mathalon dan Hill, 2014). Buih yang terlihat dihilangkan. Sedimen 500 gram dimasukkan ke dalam erlenmeyer dan dibuat larutan garam jenuh dengan densitas $1.35 \mathrm{~g} / \mathrm{cm}^{3}$ (360 g $\mathrm{NaCl} / 1 \mathrm{H}_{2} \mathrm{O}$ - kelarutan $\mathrm{NaCl}$ pada suhu $25^{\circ} \mathrm{C}$ ) ditambahkan sebanyak $750 \mathrm{ml}$, kemudian diaduk sehingga terbentuk supernatan. Pencampuran dari air suling dengan $\mathrm{NaCl}$ tersebut 
membuat partikel yang memiliki massa jenis lebih rendah akan mengapung, sedangkan yang memiliki massa jenis lebih berat akan tenggelam. Mikroplastik umumnya memiliki rentang densitas yang luas, tetapi yang paling sering ditemukan berkisar $0,8 \mathrm{~g} / \mathrm{cm}^{3}$ hingga $1,4 \mathrm{~g} / \mathrm{cm}^{3}$, sedangkan sedimen pasir dan partikel sedimen rata-rata sekitar 2,65 g/ $\mathrm{cm}^{3}$ (Hidalgo-Ruz et $a l ., 2012$ ). Setelah 6 jam, supernatan yang telah diekstraksi dari campuran sedimen dan $\mathrm{NaCl}$ disaring (Cordova et al., 2018) menggunakan kertas saring Whatman nomor 42 dengan diameter pori 2,5 $\mu \mathrm{m}$. Ekstraksi dapat dilakukan lebih dari satu kali untuk memastikan tidak ada partikel mikroplastik yang tertinggal, dengan melakukan langkah yang sama yaitu mencampurkan $\mathrm{NaCl}$ jenuh $750 \mathrm{ml}$. Ukuran pori kertas saring Whatman yang kecil, membuat proses penyaringan membutuhkan waktu yang lama, sehingga dapat menggunakan vacum pump untuk mempercepat proses pemfilteran (apabila diperlukan). Pemilahan partikel mikroplastik secara visual melalui mikroskop dan dikelompokkan dalam empat jenis yaitu film, fiber, fragmen dan pelet.

\subsection{Uji FT-IR}

Sampel yang sudah dipreparasi selanjutnya akan dianalisa menggunakan FT-IR spectroscopy di Laboratorium Fisika Fakultas Matematika dan Ilmu Pengetahuan Alam (FMIPA) Universitas Negeri Semarang. Sampel yang diujikan FT-IR adalah 3 sampel tambahan (sampel A, sampel B dan sampel C), pengujian dilakukan hanya pada perwakilan sampel A, B, C saja karena bertujuan untuk mengetahui jenis mikroplastik yang ditemukan di sedimen lamun Pulau Panjang dilihat dari gugus fungsinya.

Prinsip kerja FTIR adalah mengenali gugus fungsi suatu senyawa dari absorbansi inframerah yang dilakukan terhadap senyawa tersebut (Sjahfirdi et al. 2015). Mid-IR (400 - $4000 \mathrm{~cm}^{1}$ ) adalah wilayah yang paling umum digunakan untuk analisis karena semua molekul memiliki frekuensi absorban karakteristik dan getaran molekul primer dalam kisaran ini. Metode Midspektroskopi inframerah didasarkan pada mempelajari interaksi radiasi inframerah dengan sampel. Spektrum IR diukur dengan menghitung intensitas radiasi IR sebelum dan sesudah melewati sampel dan spektrum secara tradisional diplot dengan unit sumbu Y sebagai absorbansi atau transmitansi dan sumbu $\mathrm{X}$ sebagai unit bilangan gelombang (Davis dan Mauer, 2010). Hasil dari panjang gelombang tersebut kemudian dicocokkan dengan tabel instrumen FT-IR. Hal ini sesuai dengan Veerasingam et al., (2020) yang menyatakan bahwa spektrum inframerah mewakili sidik jari sampel (mikroplastik) dengan puncak serapan sesuai dengan frekuensi getaran antara ikatan atom penyusun bahan. Setiap bahan polimer yang 
berbeda juga akan menghasilkan spektrum inframerah yang berbeda karena tidak ada dua senyawa yang menghasilkan spektrum inframerah yang persis sama.

\subsection{Analisis Data}

Hasil mikroplastik yang sudah diperoleh dari 500 gram sedimen kering masing-masing titik kemudian dihitung jumlahnya, selanjutnya dikelompokkan menurut bentuknya (fragmen, film, fiber atau pelet). Selain itu, akan dihitung jumlah mikroplastik total yang telah didapatkan dari semua titik untuk dikelompokkan menurut ukurannya. Penggolongan ukuran mikroplastik dibagi menjadi 6 segmen yaitu 10-50 $\mu \mathrm{m}, 51-100 \mu \mathrm{m}, 101-50 \mu \mathrm{m}, 151-200 \mu \mathrm{m}$, 201-250 $\mu \mathrm{m}$ dan 251-300 $\mu \mathrm{m}$.

Analisis data dilakukan untuk mengetahui hubungan antar variabel menggunakan aplikasi SPSS 16.0. Uji statistika yang dilakukan adalah uji One Way ANOVA. Uji normalitas yang digunakan adalah Shapiro-Wilk, dikarenakan data pada penelitian ini berjumlah sedikit (kurang dari 50 data). Penjelasan output uji normalitas Shapiro-Wilk:

- Jika nilai Sig. > 0,05 maka data berdistribusi normal

- Jika nilai Sig. < 0,05 maka data tidak berdistribusi normal

Selanjutnya jika data sudah dipastikan berdistribusi normal (sig > 0,05) maka syarat kedua untuk dapat melakukan uji One Way ANOVA adalah data harus homogen. Hal ini dapat dilakukan dengan uji homogenitas. Setelah data dipastikan homogen dan berdistribusi normal, selanjutnya adalah uji One Way ANOVA untuk mengetahui apakah terdapat perbedaan rata-rata bentuk mikroplastik yang ditemukan di setiap titiknya. Interpretasi output uji One Way ANOVA:

- Jika nilai Sig. > 0,05 maka data memilili rata-rata yang sama

- Jika nilai Sig. < 0,05 maka data memiliki rata-rata yang berbeda

\section{HASIL DAN PEMBAHASAN}

\subsection{Pengukuran Variabel Pendukung}

Variabel pendukung dalam penelitian ini meliputi salinitas, kedalaman perairan serta kecepatan arus. Pengukuran variabel pendukung dapat dilihat pada Tabel 1. Salinitas yang diperoleh tidak terlalu signifikan perbedaannya berkisar antara 33 - 36 ppt. Berdasarkan pengukuran yang telah dilakukan, nilai kedalaman yang diperoleh berkisar $35-85 \mathrm{~cm}$. Kedalaman dapat mempengaruhi keberadaan lamun. 
Tabel 1. Pengukuran variabel pendukung

\begin{tabular}{cccc}
\hline Titik & Salinitas (ppt) & Kedalaman Perairan $(\mathbf{c m})$ & Arus (m/s) \\
\hline 1 & 34 & 65 & 0,043 \\
\hline 2 & 34 & 76 & 0,03 \\
\hline 3 & 36 & 57 & 0,083 \\
\hline 4 & 35 & 66 & 0,058 \\
\hline 5 & 35 & 35 & 0,067 \\
\hline 6 & 35 & 85 & 0,038 \\
\hline 7 & 33 & 58 & 0,067
\end{tabular}

Menurut Ardiannanto et al. (2014) Kedalaman rata rata kelompok terumbu karang dan lamun berkisar antara $20 \mathrm{~cm}$ sampai 3 meter. Kecepatan arus didapatkan berkisar 0,023$0,083 \mathrm{~m} / \mathrm{s}$ yang tergolong arus sangat lambat. Menurut Welch (1980), kecepatan arus terbagi dalam arus sangat cepat $(>1 \mathrm{~m} / \mathrm{s})$, arus cepat $(0,5-1 \mathrm{~m} / \mathrm{s})$, arus sedang $(0,25-0,5 \mathrm{~m} / \mathrm{s})$, arus lambat $(0,1-0,25 \mathrm{~m} / \mathrm{s})$, dan arus sangat lambat $(<0,1 \mathrm{~m} / \mathrm{s})$. Nilai arus yang diperoleh dipengaruhi oleh pasang surut dimana pada saat penelitian dilakukan, kondisi pantai masih dalam keadaan surut. Selain dipengaruhi oleh pasang surut, pola arus juga dipengaruhi oleh angin. Menurut Munasik et al. (2006) Tampaknya pola arus di Pulau Panjang menunjukkan kesamaan dengan pola pasang surut yang merupakan kombinasi pengaruh angin dan kedalaman perairan. Arus dapat membawa material mikroplastik melalui massa air. Menurut Purba, et al. (2018) Kelimpahan sampah laut di Indonesia berasal dari dua sumber, melalui arus laut yang terhubung antara Samudra Pasifik ke Samudra Hindia dan sungai-sungai.

Pengukuran variabel pendukung pada titik 1- 7 dapat dilihat pada Tabel 2. Titik 1-7 memiliki jenis lamun Cymodocea rotundata, Cymodocea serrulata, dan Enhalus acoroides. Jenis lamun yang ada di Pulau Panjang yaitu Thalassia sp, Cymodocea sp, Enhallus sp, Halodulle sp dan Siryngodium sp (Prasetya, et al. 2015). Kerapatan lamun yang ditemukan berkisar 68 tegakan $/ \mathrm{m}^{2}$ (titik 5) sampai dengan 262 tegakan $/ \mathrm{m}^{2}$ (titik 1). Menurut Supriadi, et al. (2012), dijelaskan bahwa kategori kerapatan lamun yang rendah bernilai $<50$ tegakan $/ \mathrm{m}^{2}$, kepadatan yang sedang yakni bernilai 50-100 tegakan $/ \mathrm{m}^{2}$ serta kepadatan yang tinggi bernilai > 100 tegakan $/ \mathrm{m}^{2}$. 
Tabel 2. Pengukuran variabel pendukung

\begin{tabular}{cccc}
\hline Titik & Spesies & $\begin{array}{c}\text { Jumlah } \\
\text { Tegakan } / \mathrm{m}^{2}\end{array}$ & $\begin{array}{c}\text { Klasifikasi Kerapatan Lamun } \\
\text { (Supriadi, } \text { et al. 2012) }\end{array}$ \\
\hline 1 & Cymodocea serrulata & 262 & Tinggi \\
\hline 2 & Cymodocea rotundata & 172 & Tinggi \\
\hline 3 & Cymodocea rotundata & 141 & Tinggi \\
\hline 4 & Cymodocea rotundata & 173 & Tinggi \\
& Enhalus acoroides & 5 & Sedang \\
\hline 5 & Cymodocea rotundata & 56 & Tinggi \\
& Cymodocea serrulata & 12 & Tinggi \\
\hline 6 & Cymodocea rotundata & 34 & \\
\hline 7 & Cymodocea serrulata & 74 & 143 \\
\hline
\end{tabular}

Berdasarkan pengamatan, dari titik 1 - 7 hanya ada 1 titik yang mempunyai kerapatan sedang, yaitu titik 5 sejumlah 68 tegakan $/ \mathrm{m}^{2}$, sedangkan 6 titik lainnya memiliki kerapatan lamun yang tinggi (>100 tegakan $/ \mathrm{m}^{2}$ ). Semakin rapat lamun, semakin kuat kemampuannya untuk menangkap sedimen, namun persebaran mikroplastik bukan hanya dipengaruhi oleh kerapatan lamun, namun juga faktor lain. Belum dapat diketahui secara pasti faktor apa yang paling mempengaruhi persebaran mikroplastik, namun beberapa peneliti menduga bahwa persebaran mikroplastik di laut disebabkan oleh angin dan arus (Yudhantari et al. 2019).

Berdasarkan uji stastika One Way ANOVA (Tabel 3) yang telah dilakukan didapatkan hasil nilai signifikansinya sebesar $0,008(<0,05)$ yang menunjukkan bahwa rata-rata jumlah mikroplastik berdasarkan bentuknya adalah berbeda secara signifikan.

Tabel 3. Uji One Way ANOVA

\begin{tabular}{l|r|r|r|r|r|}
\hline \multicolumn{7}{l|}{ ANOVA } & & \\
\hline Jumlah & & & & & \multicolumn{1}{c|}{ Sig. } \\
\hline & Sum of Squares & df & Mean Square & F & .008 \\
\hline Between Groups & 139.143 & 2 & 69.571 & 6.389 & \\
\hline Within Groups & 196.000 & 18 & 10.889 & & \\
\hline Total & 335.143 & 20 & & & \\
\hline
\end{tabular}

\subsection{Hasil Mikroplastik Yang Ditemukan Berdasarkan Ukurannya}

Mikroplastik yang diperoleh dari ekstraksi sebelumnya kemudian dihitung jumlahnya (Gambar 4) dan diamati menggunakan mikroskop Olympus dengan tipe SZ61 yang sudah dilengkapi kamera serta disambungkan ke laptop yang sudah terinstal aplikasi ScopeImage. Pengamatan dilakukan dengan menggunakan perbesaran mikroskop yang berbeda-beda tergantung dengan obyeknya. 
Hasil mikroplastik yang diperoleh dari titik $1-7$ total berjumlah 93 partikel yang dikelompokkan kedalam bentuk fragmen, fiber, film dan pelet dan setelah digolongkan berdasarkan ukurannya, terdiri dari 46 partikel yang berukuran $10-50 \mu \mathrm{m}, 29$ partikel (ukuran $51-100 \mu \mathrm{m}$ ), 11 partikel (ukuran $101-150 \mu \mathrm{m}$ ), 4 partikel (ukuran $151-200 \mu \mathrm{m}$ ), 1 partikel $(201-250 \mu \mathrm{m})$ dan 2 partikel untuk ukuran $251-300 \mu \mathrm{m}$.

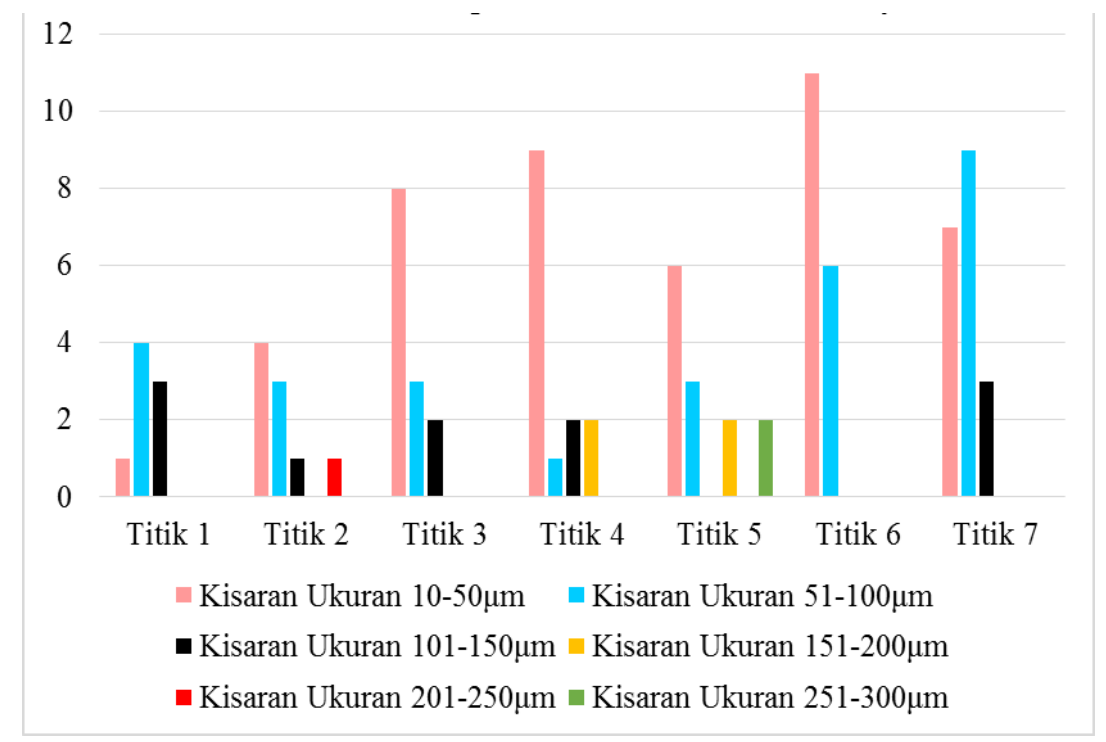

Gambar 3. Diagram jumlah mikroplastik berdasarkan ukurannya

Mikroplastik yang tersebar di suatu daerah dipengaruhi pula oleh karakteristik wilayah itu sendiri baik dari kondisi fisika, kimia maupun biologinya. Kelimpahan di sungai, pantai, muara dapat berbeda. Seperti hasil penelitian mikroplastik yang dilakukan oleh Laila et al. (2020), dimana dalam penelitian yang dilakukan di Pantai Mangunharjo Semarang bahwa rata rata kelimpahan mikroplastik mempunyai hasil Stasiun I pada ekosistem pantai sebesar 8.107 partikel/m3, Stasiun II (ekosistem sungai) sejumlah 4.523 partikel/m3 sedangkan stasiun III (ekosistem mangrove) 3.585 partikel/m3. Perbedaan hasil kelimpahan mikroplastik di masing-masing stasiun dipengaruhi oleh adanya perbedaan aktivitas di masing-masing ekosistem tersebut. Di Pantai Mangunharjo terdapat kegiatan penangkapan ikan menggunakan jarring nylon, di sungai terdapat limbah hasil rumah tangga dan industri, begitupun dengan mangrove dan muara yang menjadi tempat penumpukan sampah. Sama halnya dengan Pulau Panjang yang merupakan pantai wisata sehingga mikroplastik yang diperoleh kemungkinan besar berasal dari kegiatan pawirisata di tempat tersebut. Jika dibandingkan dengan penelitian tersebut makan mikroplastik di sedimen lamun Pulau Panjang Jepara tergolong sedikit. Namun belum ada pedoman untuk mengkategorikan apakah jumlah mikroplastik dalam suatu wilayah menggambarkan lingkungan yang tercemar 
berat, sedang atau ringan. Gugus fungsi suatu senyawa dapat diketahui dengan menggunakan alat FT-IR. Prinsip kerja FTIR adalah mengenali gugus fungsi suatu senyawa dari absorbansi inframerah yang dilakukan terhadap senyawa tersebut (Sjahfirdi et al. 2015). Mid-IR (400 $4000 \mathrm{~cm}^{1}$ ) adalah wilayah yang paling umum digunakan untuk analisis karena semua molekul memiliki frekuensi absorban karakteristik dan getaran molekul primer dalam kisaran ini. Uji FTIR sampel A, B dan C dapat dilihat pada Gambar 4, Gambar 5 dan Gambar 6 secara berurutan. Bilangan gelombang khas sampel A dan sampel B dapat dilihat pada Tabel 4 dan Tabel 5 secara berurutan. Pengukuran variabel pendukung dapat dilihat pada Tabel 6 . Berdasarkan uji yang telah dilakukan, puncak gelombang khas sampel A, sampel B dan sampel C berkisar $1466-3700 \mathrm{~cm}^{-1}$.

Tabel 4. Bilangan gelombang khas sampel A

\begin{tabular}{ll}
\hline \multicolumn{1}{c}{ Bilangan Gelombang } & \multicolumn{1}{c}{ Gugus Fungsi } \\
\hline 3700 & $\mathrm{O}-\mathrm{H}, \mathrm{N}-\mathrm{H}$ \\
\hline 2900 & $\mathrm{C}-\mathrm{H}$ \\
\hline 1474 & $\mathrm{C}=\mathrm{C}, \mathrm{C}=\mathrm{O}$ \\
\hline
\end{tabular}

Tabel 5. Bilangan gelombang khas sampel B

\begin{tabular}{ll}
\hline Bilangan Gelombang & Gugus Fungsi \\
\hline 3500 & N-H \\
\hline 2800 & C-H \\
\hline 1466 & C \\
\hline
\end{tabular}

Tabel 6. Pengukuran variabel pendukung

\begin{tabular}{ll}
\hline Bilangan Gelombang & Gugus Fungsi \\
\hline 3400 & $\mathrm{~N}-\mathrm{H}, \mathrm{OH}$ \\
\hline 2900 & $\mathrm{C}-\mathrm{H}$ \\
\hline 1474 & $\mathrm{C}=\mathrm{C}, \mathrm{C}=\mathrm{O}$ \\
\hline
\end{tabular}

Kisaran tersebut menunjukkan bahwa senyawa yang terkandung merupakan jenis plastik PP (polypropylene). PP Adalah sebuah polimer termoplastik yang dibuat oleh industri kimia dan digunakan dalam berbagai aplikasi, diantaranya adalah untuk kantong plastik, gelas plastik, ember dan botol (Asgar dan Musaddad, 2006). Hal ini dapat dibuktikan dengan adanya makroplastik yang tersaring merupakan bekas bungkus makanan (dapat dilihat kasat mata). 


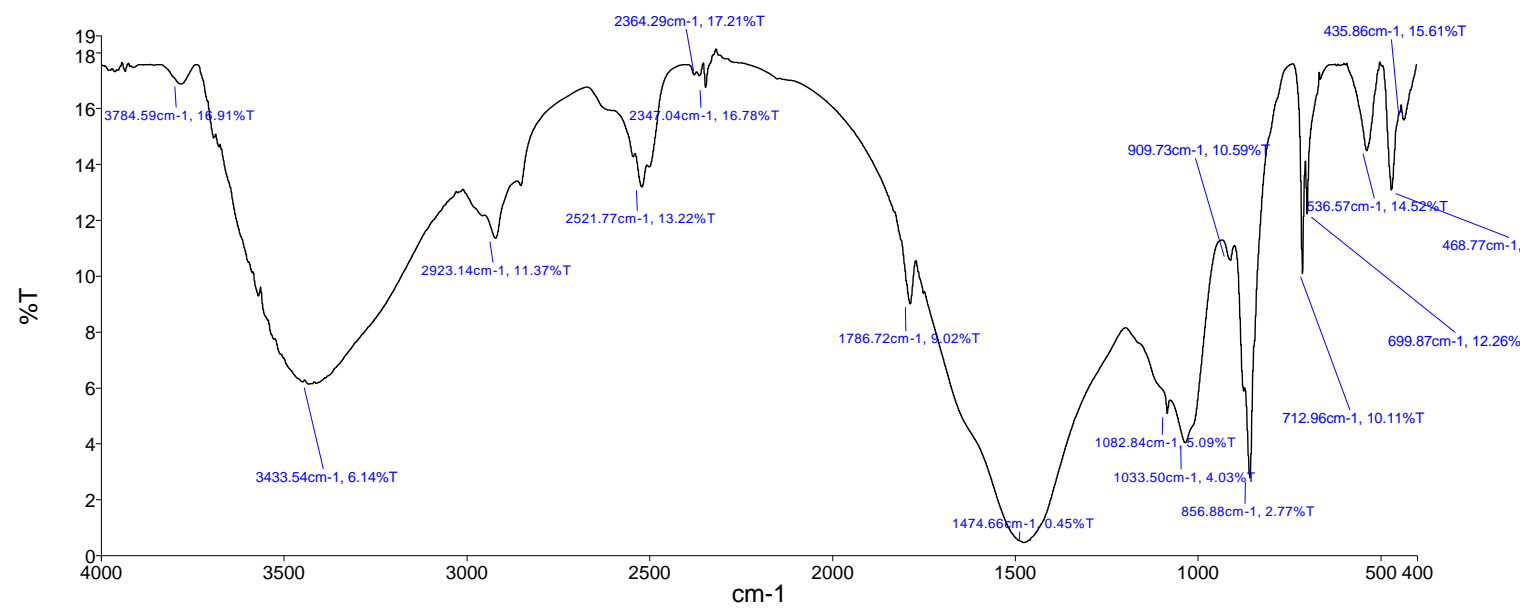

Gambar 4. Grafik FT-IR sampel A

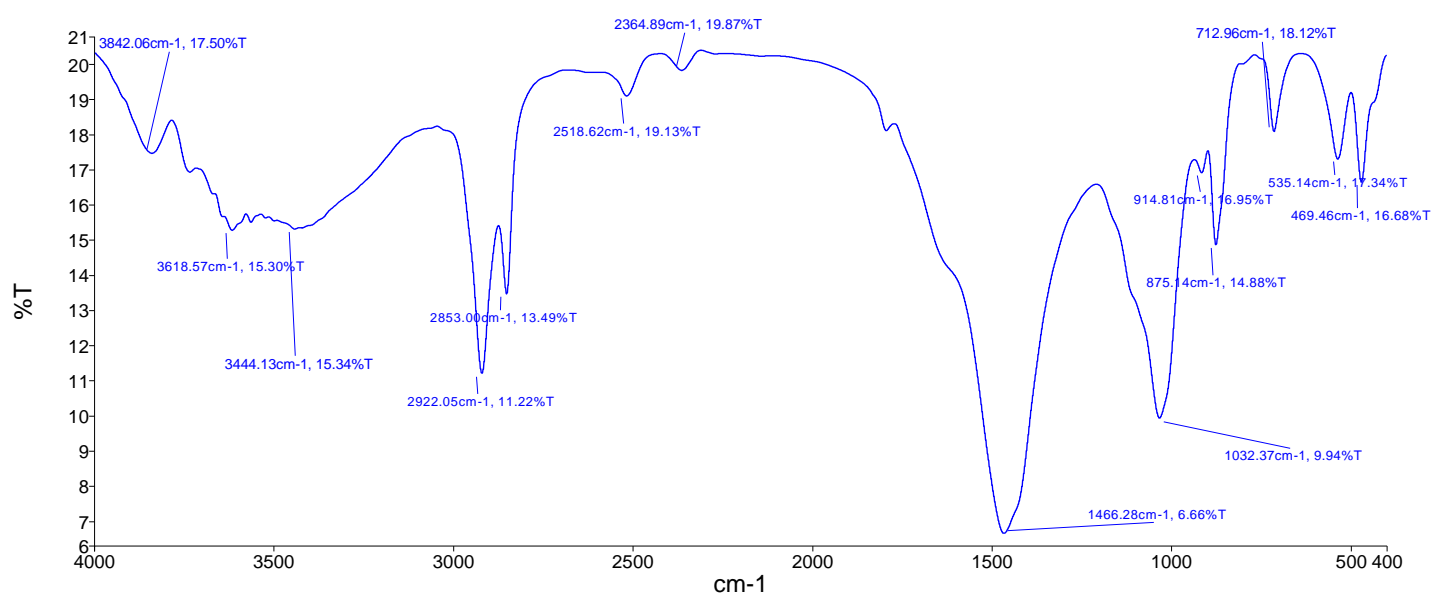

Gambar 5. Grafik FT-IR sampel B

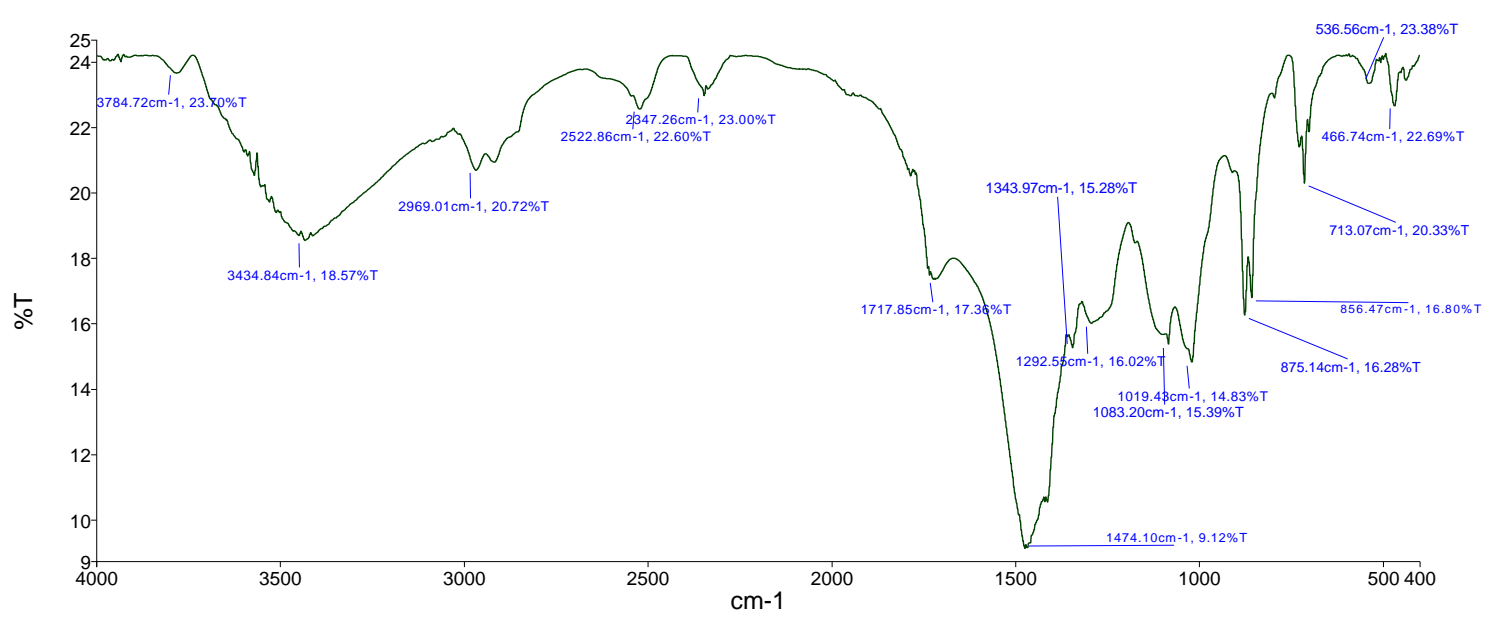

Gambar 6. Grafik FT-IR sampel C 


\subsection{Faktor Yang Mempengaruhi Bentuk Mikroplastik}

Berdasarkan penelitian yang telah dilakukan, mikroplastik yang ditemukan dari titik 1-7 didominasi oleh bentuk fragmen sebanyak 51 buah Pengelompokkan mikroplastik berdasarkan bentuknya dapat dilihat pada Gambar 7. Menurut Septian et al. (2018), dijelaskan bahwa ciri utama dari mikroplastik fragmen adalah bentuknya yang berbentuk pecahan dari plastik, tidak seperti film yang berbentuk lembaran atau fiber yang berbentuk seperti serabut. Fragmen merupakan pecahan plastik pada sampah botol, toples, map mika dan potongan kecil pipa paralon. Dapat terlihat jelas di mikroskop, beberapa mikroplastik yang didapatkan merupakan pecahan dari kemasan suatu produk, misalnya kemasan makanan. Siregar dan Yealta (2018), menjelaskan bahwa sampah plastik laut bisa berasal dari daratan (land-based sources) atau aktivitas yang berbasis di perairan laut (sea-based sources), tetapi land-based sources menyumbang 80\%. Meskipun begitu, menurut Tamminga et al., (2018), bahwa sampah in situ dari penangkapan ikan atau pengiriman (komersial dan rekreasi) langsung menambah polusi mikroplastik di ekosistem laut.

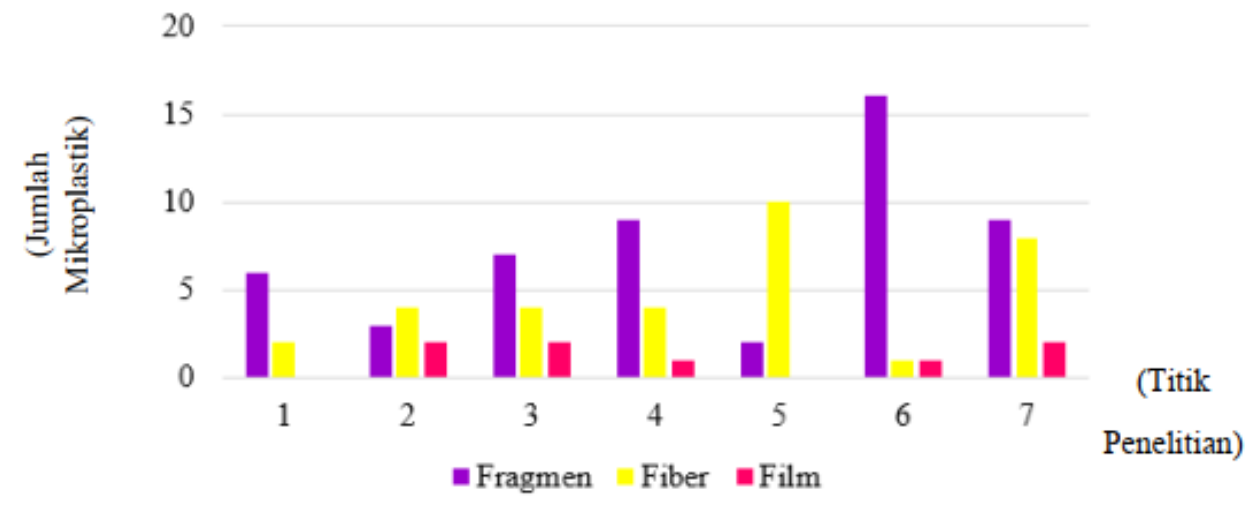

Gambar 7. Pengelompokkan mikroplastik berdasarkan bentuknya

Warna mikroplastik yang diamati yaitu dominan biru dan merah, namun terdapat warna lain juga seperti hijau, hitam dan transparan. Selain mikroplastik, ditemukan juga makroplastik yang berukuran $>5 \mathrm{~mm}$. Makroplastik tersebut sudah tidak utuh, dan tertimbun di dalam sedimen. Bentuk makroplastik yang tidak utuh bisa jadi sudah terpecah melalui berbagai proses, sehingga menjadi mikroplastik. Sumber sampah plastik lain berasal dari sampah rumah tangga, bungkus makanan, minuman, botol, sedotan dan lainnya yang digolongkan sebagai penyumbang limbah terbesar dan menyebabkan rusaknya keseimbangan lingkungan (Asia dan Arifin, 2017). European Commission (2011), menjelaskan bahwa di laut maupun darat, plastik cenderung terpecah menjadi ukuran yang lebih kecil, dipengaruhi oleh radiasi ultraviolet, gelombang dan angin. Plastik yang mengambang akan lebih mudah rusak 
dibanding dengan yang tenggelam di dasar karena air dapat menyerap sinar UV, sedangkan jika di dasar tidak ada radiasi UV dan suhunya lebih dingin dibandingkan permukaan. Selain melalui proses fisika, pemecahan plastik juga dapat dipengaruhi secara biologi yaitu melalui konsumsi plastik oleh biota laut dan proses pemecahan oleh dekomposer.

Plastik yang sebelumnya berukuran besar, akan terpecah menjadi ukuran yang lebih kecil, begitu seterusnya dan tidak akan berhenti meskipun membutuhkan waktu yang lama. Menurut Klein et al., (2018), dijelaskan bahwa degradasi mekanis tidak berhenti jika partikel berada di dalam kisaran ukuran plastik mikro, karena setelah berukuran mikro pun, akan terpecah menjadi ukuran nano. Plastik yang sudah terpecah menjadi berbagai bentuk dan ukuran akan tersebar ke berbagai kolom perairan. Menurut Costa et al., (2009), dijelaskan bahwa plastik pelet dan fragmen sering ditemukan mengambang di permukaan laut, diendapkan di bagian bawah, atau di pantai berpasir. Jumlah mikroplastik yang ditemukan berdasarkan penelitian di sedimen lamun Pulau Panjang Jepara tergolong lebih sedikit dibandingkan dengan beberapa wilayah lain di Indonesia. Gambar dari mikroplastik yang ditemukan yaitu fiber, film dan fragmen dapat dilihat pada Gambar 8.

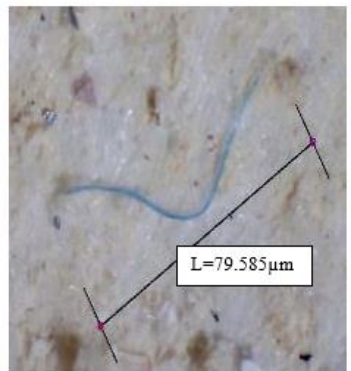

(a) Fiber (perbesaran 25x)

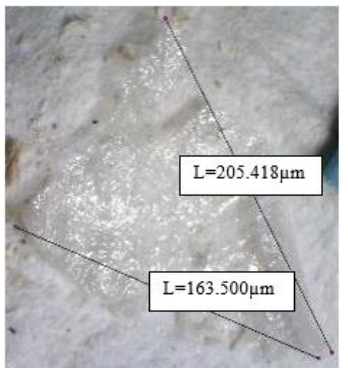

(b) Film (perbesaran 6,7x)

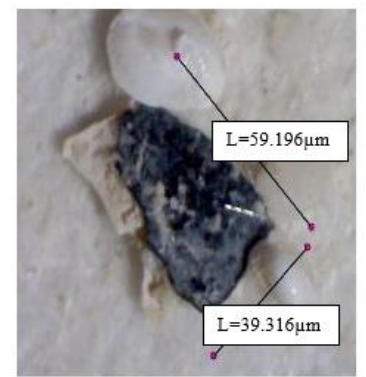

(c) Fragmen (perbesaran 20x)

Gambar 8. Mikroplastik yang ditemukan 
Lamun biasanya hidup di substrat berpasir. Menurut Setyawan, et al. (2014), dijelaskan bahwa substrat dasar pada lingkungan ekosistem lamun didominasi oleh pasir, termasuk di Pulau Panjang. Karakteristik substrat lamun di Pulau Panjang adalah berpasir putih dengan butiran yang tidak terlalu halus dan banyak tercampur dengan pecahan cangkang dan juga karang, karena di Pulau Panjang juga terdapat ekosistem karang.

\subsection{Ancaman Mikroplastik Di Lamun}

Lamun dapat tumbuh dengan baik di wilayah tropis dan di perairan dangkal. Pengaruh lamun terhadap sedimen yaitu daun lamun dapat memperlambat arus dan menahan sedimen, sehingga sedimen akan terendap di dasar perairan. Menurut Sjafrie et al. (2018), bahwa padang lamun menangkap dan menstabilkan sedimen, sehingga air menjadi lebih jernih. Ketika gelombang air mengenai padang lamun, energinya menjadi turun, sehingga sedimen yang terlarut di air bisa mengendap ke dasar laut. Ketika sedimen terendapkan di dasar, sistem perakaran padang lamun menjebak dan menstabilkan sedimen tersebut.

Semakin rapat dan lebat lamun, maka kemampuan sebagai sediment trapper semakin kuat dan sedimen yang terperangkap akan semakin banyak. Proses pengumpulan sedimen oleh padang lamun akan membuat gundukan pada dasar perairan, yang dapat digunakan sebagai habitat bagi hewan asosiasi (Azkab, 2014). Air yang mengalir membawa sedimen, nutrien, sampah, dan material lainnya. Sampah yang terbawa akan terendap dan mengambang di permukaan. Sampah (plastik) yang terendap di sedimen akan terurai menjadi ukuran yang lebih kecil melalui berbagai proses, meskipun membutuhkan waktu yang lama.

Mikroplastik mengancam biota bentik dan pelagis, apalagi pada perairan yang dangkal, dimana karakteristik perairan yang dangkal adalah airnya yang mudah tercampur, sehingga kemungkinan biota memakan mikroplastik lebih besar, dalam hal ini lamun di Pulau Panjang tergolong berada di kedalaman yang dangkal. Mikroplastik berpotensi mengancam lebih serius dibanding dengan material plastik yang berukuran besar sebagai organisme yang mendiami tingkatan tropik yang lebih rendah, seperti plankton yang mempunyai partikel rentan terhadap proses pencernaan mikroplastik sebagai akibatnya dapat mempengaruhi organisme tropik tingkat tinggi melalui proses bioakumulasi (Dewi et al. 2015).

Berdasarkan penelitian sebelumnya, mikroplastik sudah menyebabkan kematian pada organisme laut yang berukuran besar seperti mamalia laut, burung laut dan penyu (Coppock et al., 2017; Cordova et al., 2018). Bahkan, menurut Nerland et al., (2014), dijelaskan bahwa 
beberapa biota bentik sudah terbukti menelan mikroplastik yaitu tiram, kerang biru, lobster, dan teritip. Bagi biota asosiasi, keberadaan mikroplastik di ekosistem lamun menjadi ancaman yang serius salah satunya bagi teripang. Teripang (Holothuroidea) merupakan salah satu biota bentos penghuni daerah pesisir khususnya di lingkungan terumbu karang dan lingkungan pantai berlamun (Ardiannanto et al. 2014). Beberapa jenis teripang sudah ditemukan mengonsumsi mikroplastik diantaranya Holothurians (teripang) Thyonella gemmate, Holothuria floridana, Holothuria grisea dan Cucumaria frondosa (Wright et al., 2013).

\section{KESIMPULAN}

Total mikroplastik yang ditemukan dari 7 titik berjumlah 93 partikel. Titik 1 sejumlah 8 partikel, titik 2 sejumlah 9 partikel, titik 3 sejumlah 13 partikel, titik 4 sejumlah 14 partikel, titik 5 sejumlah 12 partikel, titik 6 sejumlah 18 partikel dan titik 7 sejumlah 19 partikel. Bentuk mikroplastik yang ditemukan terdiri fragmen berjumlah 51 partikel $(54,83 \%)$, fiber 34 partikel $(36,56 \%)$ dan film sebanyak 8 partikel $(8,6 \%)$. Berdasarkan uji FT-IR yang telah dilakukan terhadap 3 sampel perwakilan yaitu sampel A, sampel B dan sampel C, puncak gelombang khas ketiga titik tersebut berkisar 1466-3700 $\mathrm{cm}^{-1}$ dengan gugus fungsi N-H, O$\mathrm{H}, \mathrm{C}-\mathrm{H}, \mathrm{C}=\mathrm{C}$ dan $\mathrm{C}=\mathrm{O}$ dimana kisaran tersebut menunjukkan bahwa senyawa yang terkandung merupakan jenis plastik PP (polypropylene).

\section{DAFTAR PUSTAKA}

Ardiannanto, R., Sulardiono, B., dan Purnomo, P.W. (2014). Studi Kelimpahan Teripang (Holothuriidae) pada Ekosistem Lamun Dan Ekosistem Karang Pulau Panjang Jepara. Diponegoro Journal Of Maquares, 3(2): 66-73

Asia dan Arifin, M. Z. (2017). Dampak Sampah Plastik Bagi Ekosistem Laut. Pojok Ilmiah, 14 (1): 44-48.

Azkab, M.H. (2014). Peran Padang Lamun untuk Kehidupan Hewan Asosiasi. Oseana, 39(2): 49-54.

Coppock R. L., Cole M., Lindeque P. K., Queiros A. M., and Galloway T. S. (2017) A smallscale, portable method for extracting microplastics from marine sediments. Environmental Pollution, 230:829-837.

Cordova, M.R., Hadi, T.A and Prayudha, B. (2018). Occurrence And Abundance Of Microplastics In Coral Reef Sediment: A Case Study In Sekotong, Lombok-Indonesia. AES Bioflux, 10 (1). 
Costa, M.F., Ivar do Sul, J.A.., Da Silva, J.S., Araujo,M.C.B., Spengler, A and Tourinho, P.S. (2009). On the importance of size of plastic fragments and pellets on the strandline: a snapshot of a Brazilian beach. Environ Monit Assess, 168(1-4):299 - 304

Dewi, I. S., Budiyarsa A. A dan Ritonga I. R. (2015). Distribusi Mikroplastik pada Sedimen di Muara Badak, Kabupaten Kutai Kartanegara. DEPIK, 4(3):121-131

European Commission. (2011). Plastic Waste: Ecological and Human Health Impacts. Science for Environment Policy. In-depth Reports

Hamdalah, A. (2013). Efektivitas Media Cerita Bergambar Dan Ular Tangga dalam Pendidikan Kesehatan Gigi dan Mulut Siswa SDN 2 Patrang Kabupaten Jember. Jurnal Promkes, 1(2): 118-123

Hidalgo-Ruz, V., Gutow.L., Thompson, R.C., and Thiel, M. (2012). Microplastics in the Marine Environment: A Review of the Methods Used for Identification and Quantification. Environmental Science \& Technology, 46(6): 3060-3075

Hollman, P., Bouwmeester, H., and Peters R.J.B. (2013). Microplastics in Aquatic Food Chain: Sources, Measurement, Occurrence and Potential Health Risks. RIKILTInstituteof Food Safety Research report: Wageningan

Klein, S., Dimzon, I.K., Eubeler, J., and Knepper, T.P. (2018). Analysis, Occurrence, and Degradation of Microplastics in the Aqueous Environment. Hdb Env Chem, 58.

Laila, Q.N., Purnomo,P.W., dan Jati, O.E. (2020). Kelimpahan Mikroplastik Pada Sedimen Di Desa Mangunharjo, Kecamatan Tugu, Kota Semarang. Jurnal Pasir Laut, 4(1): 2834

Mathalon, A and Hill, P. (2014). Microplastic Fibers in the Intertidal Ecosystem Surrounding Halifax Harbor, Nova Scotia. Marine Pollution Bulletin, 81(1): 69-79

Miswanto dan Safaat, M. (2002). Dampak Pembangunan Industri Pariwisata terhadap Alih Fungsi Lahan (Studi Tentang Kehidupan Sosial Budaya Masyarakat Desa Teluk Bakau, Kecamatan Gunung Kijang, Kabupaten Bintan, Kepulauan Riau). Jurnal Antropologi: Isu-Isu Sosial Budaya,20 (1): 45-55

Munasik., Sugianto, D.N.,Pranowo, W.S., Suharsono., Situmorang, J., dan Kamiso, H.N. (2006). Pola Arus dan Kelimpahan Karang Pocillopora damicornis di Pulau Panjang, Jawa Tengah. Ilmu Kelautan,11(1): 11-18

Nerland, I.L., Halsband, C., Allan,I., and Thomas, K.V. (2014). Microplastics in Marine Environments: Occurrence, Distribution and Effects. Akvaplan-Niva, Troms $\varnothing$, Norway. Reports No. 6754-2014 
PPK-K3PK. Kementerian Kelautan dan Perikanan.

Prasetya, D.K., Ruswahyuni dan Widyorini,N. (2015). Hubungan Antara Kelimpahan Hewan Makrobenthos dengan Kerapatan Lamun yang Berbeda di Pulau Panjang dan Teluk Awur Jepara. Diponegoro Journal Of Maquares, 4 (4): 155-163

Purba, N.P., Apriliani, I.M.., Dewanti, L.D.,Herawati,H., and Faizal,I. (2018). Distribution of Macro Debris at Pangandaran Beach, Indonesia. World Scientific News, 103: 144-156

Puteri, I., Aliya,R., dan Muhammad, S.A. (2018). Penerapan Plastic Deposit Refund System Sebagai Instrumen Penanggulangan Pencemaran Limbah Plastik di Wilayah Perairan Indonesia. Jurnal Hukum Lingkungan, 4(2): 129-150

Ruiz, C.E., Esteban,M.A., and Cuesta,A. (2016). Microplastics in Aquatic Environments and Their Toxicological Implications for Fish. InTech Open: London United Kingdom (UK)

Septian, F.M., Purba, N.P., Agung, M.U.K.,Yuliadi, L.P.S., Akuan,L.F., dan P.G. Mulyani. 2018. Sebaran Spasial Mikroplastik di Sedimen Pantai Pangandaran, Jawa Barat. Jurnal Geomaritim Indonesia, 1(1): 1-8

Setyawan, B., Sulardiono,B., dan Purnomo, P.W. (2014). Kelimpahan Bulu Babi (Sea Urchin) pada Ekosistem Terumbu Karang dan Ekosistem Padang Lamun di Pulau Panjang, Jepara. Diponegoro Journal Of Maquares,3(2): 74-81

Siregar, J dan Yealta,D. (2019). Peran United Nations Environment Programme (UNEP) dalam Menangani Polusi Marine Plastic Debris di Laut Asia Timur. JOM Fisip, 6 (I.) $1-13$

Sjafrie, N.D.M., Hernawan,U.E., Prayudha,B., Supriyadi,L.H., Iswari, M.Y., Rahmat., Anggraini, K., Rahmawati,S dan Suyarso. (2018). Status Padang Lamun 2018Ver. 02. Puslit Oseanograf - LIPI: Jakarta

Supriadi., Kaswadji, R.F., Bengen, D.G., dan Hutomo, M. 2012. Komunitas Lamun di Pulau Barranglompo Makassar: Kondisi dan Karakteristik Habitat. Jurnal Maspari, 4 (2). 148-158

Tamminga, M., Hengstmann,E., and Fischer,E.K. (2018). Microplastic Analysis In The South Funen Archielago, Baltic Sea, Implementing Manta Trawling And Bulk Sampling. Marine Pollution Bulletin, 128 (2018) : 601-608

Veerasingam, S., Ranjani, M., Venkatachalapathy,R., Bagaev,A., Mukhanov,V., Litvinyuk,D., Mugilarasan,M., Gurumoorthi,K.,Guganathan,L., Aboobacker,V.M., and Vethamony,P. (2020). Contributions of Fourier Transform Infrared Spectroscopy 
In Microplastic Pollution Research: A Review. Environmental Science and Technology, 51(2021) :1-63.

Welch, E.B. (1980). Ecollogical Effect of Waste. Cambridge University Press. Cambridge. Widianarko, B dan Hantoro,I. (2018). Mikroplastik dalam Seafood Dari Pantai Utara Jawa. Semarang: Universitas Katolik Soegijapranata.

Woodall, L.C., Sanchez-Vidal,A., Canals,M., Paterson,G.L.J ., Coppock,R., Sleight,V., Calafat,A., Rogers,A.D., Narayanaswamy,B.E., and Thompson,R.C. (2015). The Deep Sea is a Major Sink for Microplastic Debris. Royal Society Open Science, 1 (140317). $\underline{\mathrm{h}}$ Wright, S.L., Thompson, R.C., and Galloway,T.S. (2013). The Physical Impacts of Microplastics on Marine Organisms: A Review. Enviromental Pollution, 178: 483-492 Yoo, J.W., Doshi,N., and Mitragotri,S. (2011). Adaptive Miccro and Nanoparticles: Temporal Control Over Carrier Properties to Facilitate Drug delivery. Advance Drug Delivery Reviews, 63 (14-15): 147-1256

Yudhantari, C.I.A.S., Hendrawan, I.G., dan Puspitha, N.L.P.R. (2019). Kandungan Mikroplastik pada Saluran Pencernaan Ikan Lemuru Protolan (Sardinella lemuru) Hasil Tangkapan di Selat Bali. JMRT, 2(2): 48-52 